\title{
FREQUENCY OF ADEQUATE HAEMODIALYSIS AT HAEMODIALYSIS UNIT NISHTAR HOSPITAL MULTAN.
}

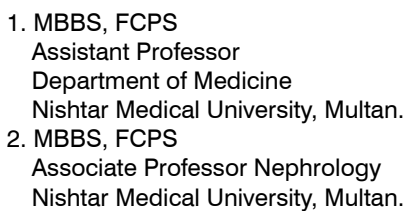

Correspondence Address:

Dr. Shahzad Alam Khan

Department of Medicine

Nishtar Medical University, Multan

shahzadalam17735@gmail.com

Article received on:

15/02/2019

Accepted for publication:

09/05/2019

Received after proof reading:

$30 / 09 / 2019$

\begin{abstract}
Shahzad Alam Khan', Ghulam Abbas ${ }^{2}$
ABSTRACT... This adequacy of HD is judged by formulas like Urea Reduction Ratio (URR) and $\mathrm{Kt} / \mathrm{V}$. Adequate hemodialysis is vital for restoration of body homeostasis towards normal and to avoid potential complications. The aim of the current study was to determine the frequency of adequate hemodialysis at hemodialysis center at Nishtar Hospital Multan. Objectives: The objective of this study was to determine the frequency of adequate hemodialysis at hemodialysis unit Nishtar Hospital Multan. Study Design: Cross-sectional Study. Setting: Department of Medicine, Medical Unit-IV, Nishtar Hospital, Multan. Duration: Six months from 18/01/2018 to 17/07/2018. Material and Methods: This study involved 174 patients undergoing hemodialysis at least 3 sessions in a week for the previous 6 months at hemodialysis center Nishtar Hospital Multan. A formal written consent was taken from every patient. Patient's demographic details along with duration of disease, calculated $\mathrm{Kt} / \mathrm{V}$ and adequacy of hemodialysis $(\mathrm{Kt} / \mathrm{V} \geq 1.2)$ were recorded in the attached proforma. Data obtained during study were analyzed by using SPSS version 24. Mean and standard deviation were estimated for numerical variables; age, duration of disease, $\mathrm{Kt} / \mathrm{V}$ values. Frequency and percentage were calculated for categorical variable i-e gender, diabetes mellitus, hypertension, adequate hemodialysis. Stratification was done for parameters like age, gender, diabetes, hypertension and duration of disease. After stratification was done t-test ws applied and value $\leq .05$ was considered as significant. Results: The age range of our study population was $40-70$ years having a mean of $54.24 \pm 8.39$ years. It included $113(64.9 \%)$ male and $61(35.1 \%)$ female suffers of ESRD. $75(43.1 \%)$ patients were diabetic while $116(66.7 \%)$ patients were hypertensive. The time lapse from diagnosis to dialysis ranged from 6-18 months with a mean of $12.11 \pm 3.55$ months. The Kt/ $\mathrm{V}$ value ranged from .80 to 1.90 with a mean of $1.45 \pm .27$. Taking a cut-off value of $\mathrm{Kt} / \mathrm{V} \geq 1.2$ for adequate hemodialysis, the frequency of adequate hemodialysis was found to be $85.1 \%(n=148)$. Conclusion: The frequency of adequate hemodialysis was found to be $85.1 \%$ among ESRD patients undergoing hemodialysis at least 3 times a week for the past 6 months at hemodialysis center Nishtar Hospital Multan. It indicates that Dialysis centre in Nishtar hospital is working effectively.
\end{abstract}

Key words: $\quad$ End Stage Renal Disease, Hemodialysis, Hemodialysis Adequacy.

Article Citation: Khan SA, Abbas G. Frequency of adequate haemodialysis at haemodialysis unit Nishtar Hospital Multan. Professional Med J 2019; 26(10):1672-1677. DOI: 10.29309/TPMJ/2019.26.10.3292

\section{INTRODUCTION}

End Stage Renal Disease (ESRD) is a distressing socioeconomic and health related problem not only for sufferers but also their dependents and family members in Pakistan. According to an estimate Pakistan has 150 End Stage Renal Disease patients/annum/million. ${ }^{1}$ ESRD is widely distributed throughout the world and the new cases of ESRD are enormously increasing in various countries. ${ }^{2,3,4}$

Haemodialysis (HD) is a traditional treatment for End Stage Renal Diseases. It is a 'life saving procedure'. Because of fiscal limitations, less than $1 / 3^{\text {rd }}$ of all patients referred to a tertiary care centre get any kind of renal replacement therapy. While most haemodialysis patients who stop treatment and die, do so because of fiscal constraints in the first three months ${ }^{5}$ Purpose of haemodialysis is to restore fluid and electrolyte balance of the body as much as possible to the normal one. Adequacy of dialysis is assessed in order to attain a dialysis dose that would be adequate enough for ESRD patients for the betterment of quality of their lives and would be helpful in prolonging their survival. ${ }^{6}$ This adequacy of HD is judged by formulas like 
$\mathrm{Kt} / \mathrm{V}$ and Urea Reduction Ratio. ${ }^{7}$

Using a cut-off value of $\mathrm{Kt} / \mathrm{V} \geq 1.2$ for adequate haemodialysis, various studies have evaluated the adequacy of several dialysis centres across the world. Roozitalab et al. ${ }^{8}$ in 2013 evaluated dialysis centres at Kohgiloyeh and Boyerahmap provinces Iran and documented that only $41.5 \%$ patients had adequate haemodialysis. Samakoosh et al. ${ }^{9}$ in 2012 determined the adequacy among haemodialysis patients at Qaemshar Razi Hospital Iran and documented that only $41.7 \%$ patients had adequate haemodialysis. Mousavi et al. ${ }^{10}$ in 2012 at Abadan (Iran) documented this rate to be $12.97 \%$. Shasti \& Babahaji ${ }^{11}$ in 2011 at Tehran (Iran) documented this rate to be $50 \%$. Mogharab et al. ${ }^{12}$ in 2010 at Birjand (Iran) documented this rate to be only $10 \%$. Hussain et al. ${ }^{13}$ in 2013 evaluated dialysis centre at Sheikh Zayed Hospital, Rahim Yar Khan Pakistan and documented that $87 \%$ of patients had adequate haemodialysis.

Adequate haemodialysis is vital for restoration of body homeostasis towards normal and to avoid potential complications. Also it is important to reduce cost of un-necessary haemodialysis and thus to reduce dropout rates. ${ }^{5}$ Assessment of adequacy of dialysis in various centres is helpful in judgement of effective functioning of that dialysis centre. It also stresses upon the need of calculating the individual's dialysis dose rather than putting the patient on dialysis in conventional way i.e 4 hours 3 times a week. By using formula of $\mathrm{Kt} / \mathrm{V}$ one is able to increase or decrease the time of dialysis or dialyser flow rate to meet adequate need of dialysis. Dialysis centre at Nishtar hospital Multan is a busy unit with haemodialysis of more than 90 patients per day. However, the haemodialysis adequacy of these patients has not been evaluated previously which necessitates this study to identify the percentage of patients receiving adequate haemodialysis. This study will bring base line data and will provide ground for future studies to identify factors attributable for inadequate haemodialysis and measures to improve this rate.

\section{OBJECTIVE}

The objective of our study was to find out the frequency of adequate hemodialysis at hemodialysis unit Nishtar Hospital Multan.

\section{OPERATIONAL DEFINITION}

\section{End Stage Renal Disease (ESRD)}

ESRD was labeled on the basis of serum creatinine $>6.5 \mathrm{mg} / \mathrm{dl}$, ultrasound finding of renal damage and glomerular filtration rate (GFR) < $10 \mathrm{ml} / \mathrm{min} / 1.73 \mathrm{~m} 2)$ for three months.

\section{Adequate Hemodialysis}

Adequacy of hemodialysis was measured in terms of post-dialysis $\mathrm{Kt} / \mathrm{V}$ and a cut-off value of $\geq 1.2$ was used for adequate hemodialysis.

\section{$\mathrm{Kt} / \mathrm{V}$}

$\mathrm{K}$ denotes dialyzer clearance, $\mathrm{t}$ notifies time for dialysis, $\mathrm{Kt}$ is product of clearance and time, $\mathrm{V}$ is water content of body. Example: If $\mathrm{K}$ is 250 $\mathrm{mL} / \mathrm{min}$ and $\mathrm{t}$ is 200 minutes ( 3 hours and 20 minutes), Kt will be $50000 \mathrm{~mL}$, or 50 liters. Water content of $60 \mathrm{~kg}$ person is $36(60 \%)$ liters. So Kt/V for this patient would be 1.67 .

\section{Duration of Disease}

It was measured in months from the date of diagnosis of ESRD (clinical record) till the enrolment in the current study.

\section{MATERIALS AND METHODS}

Research was conducted at Department of Nephrology and Medical Unit-IV, Nishtar Hospital, Multan. Duration of study was 6 months from $18^{\text {th }}$ January 2018 to $17^{\text {th }}$ July 2018 . One hundred and seventy four patients were selected by NonProbability, Consecutive Sampling. Individuals with either gender between 40-70 years of age suffering from ESRD undergoing regular hemodialysis at least 3 times a week (according to log of dialysis center) for the past 6 months. However, patients shifted from continuous ambulatory peritoneal dialysis therapy as per history and clinical record of the patient 
and patients who received acute (unplanned emergent) dialysis during last 3 months on more than one occasion according to review of medical record of the patient were excluded. After acquisition of approval of ethical review committee, 174 patients undergoing hemodialysis at least 3 sessions in a week for the previous 6 months at hemodialysis center Nishtar Hospital Multan were enrolled. A formal written consent was taken from every patient. Patient's demographic details along with duration of disease were recorded in the attached proforma. Kt/V and adequacy of hemodialysis $(K t / V \geq 1.2)$ these patients after dialysis on Fresenius $4008 \mathrm{~S}$ dialysis machine was recorded. All the patients received hemodialysis on the same machine and by the same operator to eliminate bias. Data obtained during study were analyzed by using SPSS version 24 . Mean and standard deviation were estimated for numerical variables; age, duration of disease, $\mathrm{Kt} / \mathrm{V}$ values. Frequency and percentage were calculated for categorical variable i-e gender, diabetes mellitus, hypertension, adequate hemodialysis. Stratification was done for parameters like age, gender, diabetes, hypertension and duration of disease. After stratification was done t-test was applied and value $\leq 0.05$ was considered as significant.

\section{RESULTS}

This study involved 174 patients undergoing hemodialysis at least 3 times a week for the past 6 months at hemodialysis center Nishtar Hospital Multan. The age range of our study population was $40-70$ years having a mean of $54.24 \pm 8.39$ years. It included 113 (64.9\%) male and 61 (35.1\%) female suffers of ESRD. Seventy five (43.1\%) patients were diabetic while 116 (66.7\%) patients were hypertensive. The duration of disease ranged from 6 months to 18 months with a mean of $12.11 \pm 3.55$ months.

The $\mathrm{Kt} / \mathrm{V}$ value ranged from 0.80 to 1.90 with a mean of $1.45 \pm .27$. Taking a cut-off value of $\mathrm{Kt} /$ $V \geq 1.2$ for adequate hemodialysis, the frequency of adequate hemodialysis was found to be $85.1 \%$ $(n=148)$.

When stratified, the frequency of adequate hemodialysis was un-affected by patient age; 40-50 years vs. 51-60 years vs. 61-70 years (85.0\% vs. $85.7 \%$ vs. $83.8 \%$; $p=.964)$, gender; male vs. female (85.8\% vs. $83.6 \% ; p=.693)$, diabetes status; diabetics vs. non-diabetics (82.7\% vs. $86.9 \% ; p=.441$ ), hypertensive status; hypertensive vs. normotensive (82.8\% vs. $89.7 \%$; $\mathrm{p}=.229$ ) and duration of disease; $6-9$ months vs. $10-12$ months vs. $13-15$ months vs. $16-18$ months ( $84.3 \%$ vs. $87.1 \%$ vs. $83.6 \%$ vs. $87.1 \% ; p=.955)$.

\begin{tabular}{|c|c|c|c|}
\hline \multirow[b]{2}{*}{ Age } & \multicolumn{2}{|c|}{ Hemodialysis Adequacy } & \multirow[b]{2}{*}{ P-Value } \\
\hline & $\begin{array}{l}\text { Adequate } \\
(n=148)\end{array}$ & $\begin{array}{l}\text { Inadequate } \\
(n=26)\end{array}$ & \\
\hline 40 - 50 Years & 51 & 09 & \multirow{3}{*}{0.962} \\
\hline $51-60$ Years & 66 & 11 & \\
\hline $61-70$ Years & 31 & 06 & \\
\hline \multicolumn{4}{|c|}{$\begin{array}{l}\text { Table-I. Age wise distribution of hemodialysis } \\
\text { Adequacy. }(n=174)\end{array}$} \\
\hline \multirow[b]{2}{*}{ Gender } & \multicolumn{2}{|c|}{ Hemodialysis Adequacy } & \multirow[b]{2}{*}{ P-Value } \\
\hline & $\begin{array}{l}\text { Adequate } \\
(n=148)\end{array}$ & $\begin{array}{l}\text { Inadequate } \\
(n=26)\end{array}$ & \\
\hline Male & 97 & 16 & \multirow{2}{*}{0.693} \\
\hline Female & 51 & 10 & \\
\hline \multicolumn{4}{|c|}{$\begin{array}{l}\text { Table-II. Gender wise distribution of hemodialysis } \\
\text { Adequacy. }(n=174)\end{array}$} \\
\hline \multirow[b]{2}{*}{ Diabetes } & \multicolumn{2}{|c|}{ Hemodialysis Adequacy } & \multirow[b]{2}{*}{ P-Value } \\
\hline & $\begin{array}{l}\text { Adequate } \\
(\mathrm{n}=148)\end{array}$ & $\begin{array}{l}\text { Inadequate } \\
(\mathrm{n}=26)\end{array}$ & \\
\hline Yes & 62 & 13 & \multirow{2}{*}{0.441} \\
\hline No & 86 & 13 & \\
\hline \multicolumn{4}{|c|}{$\begin{array}{l}\text { Table-III. Distribution of hemodialysis adequacy with } \\
\text { regards to diabetes. }(n=174)\end{array}$} \\
\hline \multirow[b]{2}{*}{ Hypertension } & \multicolumn{2}{|c|}{ Hemodialysis Adequacy } & \multirow[b]{2}{*}{ P-Value } \\
\hline & $\begin{array}{l}\text { Adequate } \\
(n=148)\end{array}$ & $\begin{array}{l}\text { Inadequate } \\
(n=26)\end{array}$ & \\
\hline Yes & 96 & 20 & \multirow{2}{*}{0.229} \\
\hline No & 52 & 06 & \\
\hline
\end{tabular}

Table-IV. Distribution of hemodialysis Adequacy with regards to hypertension. $(n=174)$

\begin{tabular}{|c|c|c|c|}
\hline \multirow[b]{2}{*}{ Duration } & \multicolumn{2}{|c|}{ Hemodialysis Adequacy } & \multirow[b]{2}{*}{ P-Value } \\
\hline & $\begin{array}{l}\text { Adequate } \\
(n=148)\end{array}$ & $\begin{array}{l}\text { Inadequate } \\
\qquad(n=26)\end{array}$ & \\
\hline $6-9$ months & 43 & 08 & \multirow{4}{*}{0.955} \\
\hline $10-12$ Months & 27 & 04 & \\
\hline $13-15$ Months & 51 & 10 & \\
\hline $16-18$ months & 27 & 04 & \\
\hline
\end{tabular}

Table-V. Distribution of hemodialysis Adequacy with regards to duration of disease. $(n=174)$ 


\begin{tabular}{|c|c|c|c|c|}
\hline Author & Year & Dialysis Center & Country & Adequacy \\
\hline Roozitalab et al. ${ }^{8}$ & 2013 & Kohgiloyeh and Boyerahmap & Iran & $41.5 \%$ \\
\hline Samakoosh et al. ${ }^{9}$ & 2012 & Qaemshar Razi Hospital & Iran & $41.7 \%$ \\
\hline Mousavi et al. ${ }^{10}$ & 2012 & Abadan & Iran & $12.97 \%$ \\
\hline Shasti \& Babahaji ${ }^{11}$ & 2011 & Tehran & Iran & $50 \%$ \\
\hline Mogharab et al. ${ }^{12}$ & 2010 & Birjand & Iran & $10 \%$ \\
\hline Manandhar et al. ${ }^{14}$ & 2009 & $\begin{array}{l}\text { Nepal Medical College and Teaching } \\
\text { Hospital }\end{array}$ & Nepal & $17 \%$ \\
\hline Hussain et al. ${ }^{13}$ & 2013 & $\begin{array}{l}\text { Sheikh Zayed Hospital, Rahim Yar } \\
\text { Khan }\end{array}$ & Pakistan & $87 \%$ \\
\hline Current Study & 2015 & Nishtar Hospital, Multan & Pakistan & $85.1 \%$ \\
\hline
\end{tabular}

\section{DISCUSSION}

The End Stage Renal Disease (ESRD) is a distressing medical, social, and economic problem not only for patients but also for their families. ${ }^{1}$ Haemodialysis (HD) is a traditional treatment for End Stage Renal Diseases and is a lifesaving procedure. ${ }^{5}$ Haemodialysis is aimed at returning the body's fluid and electrolyte status as close to normal as possible. This adequacy of $\mathrm{HD}$ is judged by formulas like $\mathrm{Kt} / \mathrm{V}$ and Urea Reduction Ratio. ${ }^{7}$ Adequate haemodialysis is vital for restoration of body homeostasis towards normal and to avoid potential complications also it is important to reduce cost of un-necessary hemodialysis and thus to reduce dropout rates. Using a cut-off value of $\mathrm{Kt} / \mathrm{V} \geq 1.2$ for adequate hemodialysis, various studies have evaluated the adequacy of several dialysis centers across the world. A summary of these studies and their reported frequency of adequate hemodialysis have been given in table below.

According to an estimate, Pakistan has 150 ESRD patients/annum/million ${ }^{1}$. Dialysis center at Nishtar hospital Multan is a busy unit with haemodialysis of more than 90 patients per day. The purpose of the current study was to determine the frequency of adequate hemodialysis at hemodialysis center Nishtar Hospital Multan.

This study involved 174 patients undergoing hemodialysis at least 3 times a week for the past 6 months at hemodialysis center Nishtar Hospital Multan. The age of the patients ranged from 40 years to 70 years with a mean of $54.24 \pm 8.39$ years. There were $113(64.9 \%)$ male and 61 $(35.1 \%)$ female patients in the study sample. Lu et $a{ }^{15}$ from USA has also reported very high frequency of male patient with $98 \%$, higher than our results while mean age was $66.2 \pm 11$. 3 years, showing similar trends to our results. Another study by Sumida et al $^{16}$ from USA also reported $98 \%$ male gender predominance while mean age of the study cases was $68.1 \pm 11.4$ years, similar to our trends.

Seventy Five (43.1\%) patients were diabetic while $116(66.7 \%)$ patients were hypertensive. Hussain et $\mathrm{al}^{13}$ observed a similar frequency of diabetes $(55 \%)$ but comparatively very low frequency of hypertension (17\%) among ESRD patients at hemodialysis center Sheikh Zayed Hospital, Rahim Yar Khan Pakistan. Lu et al ${ }^{15}$ from USA has also reported ESRD patients having $47 \%$ diabetes while $46 \%$ hypertension, similar to that of our study results. Another study by Sumida et al ${ }^{16}$ from USA reported $71.2 \%$ diabetes and $96 \%$ hypertension which were much higher than our study results. The reason may be higher mean age of these patients as compared to our results as we only included patients up to 70 years of age, while age is considered to be an independent risk factor for diabetes and hypertension.

The duration of disease ranged from 6 months to 18 months with a mean of $12.11 \pm 3.55$ months. The $\mathrm{Kt} / \mathrm{V}$ value ranged from 0.80 to 1.90 with a mean of $1.45 \pm .27$ while Hussain et $\mathrm{al}^{13}$ observed mean $\mathrm{Kt} / \mathrm{V}$ to be $1.22 \pm 0.04$.

Taking a cut-off value of $\mathrm{Kt} / \mathrm{V} \geq 1.2$ for adequate hemodialysis, the frequency of adequate hemodialysis was found to be $85.1 \%(n=148)$. Our results match with those of Hussain et $\mathrm{al}^{13}$ in 2013 who evaluated dialysis center at Sheikh Zayed Hospital, Rahim Yar Khan Pakistan and 
documented that $87 \%$ of patients had adequate hemodialysis.

When stratified, the frequency of adequate hemodialysis was un-affected by patient age; 40-50 years vs. 51-60 years vs. 61-70 years (85.0\% vs. $85.7 \%$ vs. $83.8 \%$; $p=.964)$, gender; male vs. female (85.8\% vs. $83.6 \% ; p=.693)$, diabetes status; diabetics vs. non-diabetics (82.7\% vs. $86.9 \% ; p=.441$ ), hypertensive status; hypertensive vs. normotensive ( $82.8 \%$ vs. $89.7 \%$; $\mathrm{p}=.229$ ) and duration of disease; $6-9$ months vs. $10-12$ months vs. $13-15$ months vs. $16-18$ months ( $84.3 \%$ vs. $87.1 \%$ vs. $83.6 \%$ vs. $87.1 \%$; $p=0.955$ ).

Thus frequency of adequate hemodialysis was found to be $85.1 \%$ among ESRD patients undergoing hemodialysis at least 3 times a week for the past 6 months at hemodialysis center Nishtar Hospital Multan and this frequency was not affected by patient age, gender, diabetes, hypertension and duration of disease. This frequency is quite high as compared to that reported in literature for other dialysis centers across the world as shown above. This is encouraging and highlights the success of dialysis center at Nishtar Hospital, Multan.

A very important limitation to our study was lack of long term follow-up to determine dropout rates and mortality as a number of previous studies have reported association between low mean $\mathrm{Kt} / \mathrm{V}$ value and patient's mortality. ${ }^{17}$ Therefore future studies with long term follow-up to evaluate frequency of mortality among ESRD patients undergoing hemodialysis at Hemodialysis Center, Nishtar Hospital Multan are recommended.

\section{CONCLUSION}

Adequacy of dialysis is assessed in order to attain a dialysis dose that would be adequate enough for ESRD patients for the betterment of quality of their lives and would be helpful in prolonging their survival. Assessment of adequacy of dialysis in various centres is helpful in judgement of effective functioning of that dialysis centre. It also stresses upon the need of calculating the individual's dialysis dose rather than putting the patient on dialysis in conventional way i.e. 4 hours 3 times a week. By using formula of $\mathrm{Kt} / \mathrm{V}$ one is able to increase or decrease the duration or dialyser flow rate to meet adequate need of dialysis

The frequency of adequate hemodialysis was found to be $85.1 \%$ among ESRD patients undergoing hemodialysis at least 3 times a week for the past 6 months at hemodialysis center Nishtar Hospital Multan. It indicates that Dialysis center in Nishtar hospital is working effectively.

Copyright@ 09 May, 2019.

\section{REFERENCES}

1. Naqvi SAJ. Renal diseases in pakistan-'time to act'. J Nephrol Ren Transplant 2009; 2(1):133-5.

2. Liyanage T, Ninomiya T, Jha V, et al. Worldwide access to treatment for end-stage kidney disease: A systematic review. Lancet 2015; 385: 1975-82.

3. Robinson BM, Akizawa T, Jager KJ, Kerr PG, Saran R, Pisoni RL. Factors affecting outcomes in patients reaching end-stage kidney disease worldwide: Differences in access to renal replacement therapy, modality use, and haemodialysis practices. Lancet 2016;388:294-306

4. Health indicators for renal replacement therapy in Saudi Arabia. Saudi J Kidney Dis Transpl 2016; 27:1839.).

5. Sakhuja V, Kohli HS. End-stage renal disease in India and Pakistan: Incidence, causes, and management. Ethn Dis 2006; 16(2):20-3.

6. Locatelli $F$, Buoncristiani $U$, Canaud $B$, Köhler $H$, Petitclerc T, Zucchelli P. Dialysis dose and frequency. Nephrol Dial Transplant 2005; 20: 285-96.

7. White $\mathrm{Y}$. Haemodialysis adequacy: looking for the holy grail. Ren Soc Australas J 2013; 9(2):94-9.

8. Roozitalab M, Moohamadi B, Najafi SH, Mehrabi S, Fararouei M. KT/V and URR and the Adequacy of Hemodialysis in Iranian provincial hospitals: An evaluation study. Life Sci J 2013; 10(12s):13-6.

9. Samakoosh MA, Aghaie N, Gholami F, Shirzad M, Yosefi E, Baboli MT. Assesment dialysis adequacy in hemodialysis patients of qaemshar razi hospital in 2012. J Mazand Univ Med Sci 2013; 23(107):20-7.

10. Mousavi SB, Nejad $\mathrm{KH}$, Zeraati AA. The evaluation of dialysis adequacy by $\mathrm{KT} / \mathrm{V}$ in hemodialysis patients. Jundishapur Sci Med J 2012; 11(1):43-8. 
11. Shasti $S$, Babahaji M. The assessment of dialysis adequacy among hemodialysis patients in Tehran City. J Med Ebnesina 2011; 14(1):23-7.

12. Mogharab M, Madarshahian F, Rezai N, Mohammadi A. Dialysis adequacy in chronic hemodialysis patients in educational center Vali-Asr in Birjand. J Birjand Uni Med Sci 2010; 17(3):206-14.

13. Hussain A, Rizwan M, Saeed K, Tariq M. Effect of increasing dialysate flow rate on achieved $\mathrm{Kt} / \mathrm{V}$ in patients on maintenance hemodialysis. J Sheikh Zayed Med Coll 2013; 4(1):414-8.

14. Manandhar DN, Chhetri PK, Tiwari R, Lamichhane S. Evaluation of dialysis adequacy in patients under hemodialysis and effectiveness of dialysers reuses. Nepal Med Coll J 2009; 11(2):107-10.
15. Lu JL, Molnar MZ, Sumida K, Diskin CD, Streja E, Siddiqui $O A$, et al. Association of the frequency of preend-stage renal disease medical care with post-endstage renal disease mortality and hospitalization. Nephrol Dial Transplant. 2018 May 1; 33(5):789-795.

16. Sumida K, Molnar MZ, Potukuchi PK, Thomas F, Lu $\mathrm{JL}$, Obi $\mathrm{Y}$, et al. Prognostic significance of pre-endstage renal disease serum alkaline phosphatase for post-end-stage renal disease mortality in latestage chronic kidney disease patients transitioning to dialysis. Nephrol Dial Transplant. 2018 Feb 1; 33(2):264-273.

17. Kimata N, Karaboyas A, Bieber BA, Pisoni RL, Morgenstern H, Gillespie BW, et al. Gender, low Kt/V, and mortality in Japanese hemodialysis patients: opportunities for improvement through modifiable practices. Hemodial Int 2014; 18(3):596-606.

\begin{tabular}{|c|c|c|c|}
\hline \multicolumn{3}{|c}{ AUTHORSHIP AND CONTRIBUTION DECLARATION } \\
\hline Sr. \# & Author-s Full Name & \multicolumn{1}{|c|}{ Contribution to the paper } & Author's Signature \\
\hline 1 & Shahzad Alam Khan & $\begin{array}{l}\text { Study planning, conception } \\
\text { manuscript writing. } \\
\text { Data collection \& Analysis. }\end{array}$ \\
\hline 2 & Ghulam Abbas & \\
\hline
\end{tabular}

